\section{УГОЛОВНО-ПРАВОВОЕ ЗНАЧЕНИЕ ФАКУЛЬТАТИВНЫХ ПРИЗНАКОВ СУБЪЕКТИВНОЙ СТОРОНЫ ПРЕСТУПЛЕНИЙ ПРОТИВ ЖИЗНИ И ЗДОРОВЬЯ ЛИЧНОСТИ}

\section{Аннотация:}

В работе рассмотрено уголовно-правовое значение факультативных признаков субъективной стороны преступлений против жизни и здоровья личности. Автором изучены особенности каждого признака, образующего названный элемент состава преступления. В работе подчеркивается, что глава 16 УК РФ закрепляет ряд преступных деяний, для которых факультативные признаки субъективной стороны преступления выступают в качестве обязательного, квалифицирующего или привилегирующего признака. Автор утверждает, что все преступления с умышленной формой винь содержат в своем составе факультативные признаки, свойственные субъективной стороне преступления. Другое дело, что они могут быть учтены непосредственно в законе, а могут присутствовать фактически, влияя на обеспечение принципа справедливости при назначении наказания. В статье делается вывод, что именно названные признаки нередко помогают разграничить смежные составы преступлений, определить форму вины, способствуют реализации процесса индивидуализации наказания.

Ключевые слова:

преступления против жизни и здоровья, факультативные признаки субъективной стороны, мотив, цель, эмоции, квалифицированный состав преступления, привилегированный состав преступления, квалификация преступления, индивидуализация наказания.

\section{CRIMINAL LEGAL VALUE OF THE OPTIONAL SIGNS OF THE SUBJECTIVE PARTY OF CRIMES AGAINST THE LIFE AND HEALTH OF THE PERSON}

The paper considers the criminal legal value of opmary: features of the subjective side of crimes against the life and health of an individual. The author has studied the the crime. The work emphasizes that chapter 16 of the Criminal Code of the Russian Federation establishes a number of criminal acts for which optional features of the subjective side of the crime act as mandatory, qualifying or privileging grounds. The author claims that all crimes with a deliberate form of guilt contain optional features characteristic of the subjective side of the crime. On the other hand, they can be taken into account directly in the law, but can actually be present, affecting the provision of the principle of justice in sentencing. The article concludes that these characteristics are the ones which often help to distinguish between related offenses, determine the form of guilt, and contribute to the implementation of the process of individualization of punishment.

Keywords: crimes against life and health, optional features of the subjective side, motive, purpose, emotions, qualified corpus delicti, privileged corpus delicti, qualification of a crime, individualization of punishment.

Совокупность определенных объективных и субъективных признаков, закрепленных в уголовном законе, является обязательной предпосылкой для формирования преступного деяния. Данная совокупность представляется составом преступления. Эта правовая категория в уголовно-правовой отрасли считается преимущественно доктринальной. Кодифицированные уголовно-правовые источники большинства стран мира не используют данное понятие. Вместе с тем, этот термин достаточно широко используется в Уголовном кодексе РФ (далее - УК РФ) и Уголовно-процессуальном кодексе РФ (далее - УПК РФ), например: ст. ст. 8, 31, УК РФ, ст. ст. 24, 302 УПК РФ и т. д., а также теории уголовного права и следственно-судебной практике.

Каждый элемент состава объединяет в себе признаки, которые в определенном преступлении своеобразны и, как правило, неповторимы.

Одним из элементов состава преступления выступает его субъективная сторона. В юридической теории и практике субъективная сторона преступления является чрезвычайно важной, что обусловлено рядом обстоятельств. Будучи составным элементом основания уголовной ответственности, субъективная сторона преступления предоставляет возможность разграничить преступное поведение и непреступное [1, с. 117]. Она отражает форму вины преступника, мотивационную составляющую субъекта преступления, целевую направленность его поведения, эмоциональное состояние лица во время совершения преступления, что в результате приводит к надлежащей и правильной квалификации преступного деяния. 
Кроме этого, субъективная сторона преступления позволяет отграничить друг от друга составы преступлений, сходные по объективным признакам [2, с. 271].

Следует отметить, что реализация личностного подхода к установлению и реализации уголовной ответственности гарантирует соблюдение таких принципов, как справедливость, законность и т. д. Для индивидуализации и дифференциации ответственности за совершение преступного деяния необходимо установить все признаки состава преступления, в том числе образующие субъективную сторону.

В отечественном законодательстве отсутствует понятие субъективной стороны преступления. Вместе с тем в науке сложился единый подход в понимании данного феномена. Под субъективной стороной преступного деяния следует понимать внутреннюю его сторону, психическую деятельность субъекта преступления, непосредственно связанную с совершением преступления [3, с. 52; 4, с. 212]. Законодатель раскрывает ее содержание путем использования таких категорий, как вина, мотив, цель. Это связано с тем, что названые признаки характеризуют именно психическую сущность преступления, причем с различных сторон, что и является основанием их отнесения к субъективной стороне.

В правовой доктрине существует спор о месте субъективной стороны в составе преступления, о взаимосвязи субъективной стороны преступления с виной, мотивом и целью, эмоциями.

Анализируя вопрос о корреляции субъективной стороны преступления и вины, следует заметить, что ряд ученых указывают на полное совпадение данных правовых категорий. Они считают, что интеллектуально-волевая деятельность человека напрямую взаимосвязана с эмоциями и мотивацией [5; 6, с. 41-42]. Данной позиции придерживаются представители других отраслей права. Например, специалисты гражданского права рассматривают субъективную сторону состава правонарушения через категорию вины [7, с. 29]. Данные выводы они делают из анализа ст. 401 ГК РФ, согласно которой лицо, не исполнившее обязательство в полном объеме либо исполнившее его в ненадлежащей форме, несет ответственность при наличии установленной вины. В науке административного права субъективную сторону правонарушения определяют через отношение правонарушителя к совершенному деянию и его последствиям, определяемое как форма вины [8, с. 26].

Таким образом, по смыслу указанных точек зрения, фракультативные признаки субъективной стороны преступления являются частью вины. Соответственно, содержание субъективной стороны исчерпывается виной, включающей в себя и другие психические процессы: мотив, цель, эмоции.

Трудно согласиться с данной позицией, так как по объему и своему содержанию субъективная сторона преступления шире вины. Прежде всего отождествление вины и субъективной стороны преступного деяния не отвечает законодательной регламентации вины. Так, в ч. 1 ст. 24 УК РФ не указываются мотив, цель и эмоции, которые в свою очередь характеризуют психическую активность субъекта в связи с совершением преступления. Указанной позиции придерживается большинство авторов, например А.И. Рарог [9, с. 7], П.С. Дагель [10, с. 78], Б.В. Епифанов [11, с. 138] и др.

Другая группа специалистов в области уголовного права утверждает, что вина шире субъективной стороны преступного деяния.

Так, по мнению Ю.А. Демидова, «вина не может сводиться к какому-либо элементу преступления, хотя бы к умыслу и неосторожности, или к деянию, взятому с его объективной стороны. Она равно выражается в объективной и субъективной сторонах преступления» [12, с. 84]. Ученый отмечал, что содержание вины необходимо видеть в совершении преступления конкретным лицом, в единстве объективных и субъективных обстоятельств, в которых выразилась вина.

Отмеченная позиция видится спорной, так как отождествление факта совершения преступления с виной означает объективирование вины, что в свою очередь лишает ее конкретной определенности как признака состава преступления, нивелирует ее содержание и самостоятельное значение.

Следующая группа ученых раскрывает субъективную сторону преступления через ее юридические признаки - вину, мотив, цель и эмоции. Данной точки зрения придерживается большинство специалистов уголовного права. Ее приверженцем является и автор статьи.

Безусловно, все признаки субъективной стороны индивидуальны, выступают самостоятельными психологическими явлениями, не охватывающими собой друг друга. В данном случае следует обратить внимание, что в психологии выделяют три категории, которые так или иначе связаны с активностью индивида, - мотив, потребность и эмоция [13, с. 118].

Как отмечал С.Л. Рубинштейн, любое действие человека исходит из тех или иных мотивов и направлено на поставленную цель, выражая определенное отношение человека к окружающему миру [14, с. 14]. 
Известный психолог А.Н. Леонтьев указывал на то, что цели, мотивы и эмоции являются самостоятельными элементами психологической активности личности [15, с. 1, 13-20, 23-28, 35-39]. В силу своей самостоятельности все элементы взаимосвязаны. Теоретик также подчеркивает, что рассматриваемые элементы зарождаются в потребности личности.

Таким образом, психология рассматривает мотив, цель и эмоции как самостоятельные элементы психической активности человека.

При квалификации преступлений против жизни и здоровья установление факультативных признаков субъективной стороны преступления имеет особое значение. Именно они во многих ситуациях позволяют разграничить преступные деяния и применить должную норму права.

Следует отметить, что применительно к неосторожному преступлению уголовное законодательство не включает в содержание субъективной стороны фракультативные признаки (мотив, цель и эмоции). По мнению Г.Ф. Цельникера, в преступлениях с неосторожной формой вины цели и мотив преступления отсутствуют [16, с. 17].

Соглашаясь с тем, что для неосторожных преступлений не следует предусматривать фракультативных признаков субъективной стороны, имеющих уголовно-правовое значение, тем не менее заметим, что и при их совершении психическая деятельность субъекта, как правило, фактически характеризуется наличием мотивов и эмоций, особенно если речь идет о преступлениях, совершаемых по легкомыслию.

Одной из проблем выступают составы преступления с формой вины, законодательством четко не определенной (например, деяния, предусмотренные ст. 110, ч. 4-6 ст. 110.1 УК РФ). В случае если такие преступления рассматривать с позиций неосторожной формы вины, то, безусловно, следует констатировать отсутствие фракультативных признаков субъективной стороны. В случае признания данных преступлений умышленными, необходимо заключить, что их субъективной стороне свойственны фракультативные признаки, - по крайней мере фактически, даже если они не предусмотрены законом в качестве признаков составов соответствующих преступных посягательств.

В частности, на необходимость выявления мотивов и цели преступления указывает Верховный Суд РФ. Так, согласно абз. 2 п. 1 постановления Пленума Верховного Суда РФ от 27.01.1999 № 1 (ред. от 03.03.2015) «О судебной практике по делам об убийстве (ст. 105 УК РФ)» [17], по каждому делу должна быть установлена форма вины, выяснены мотивы, цель и способ преступления. Выяснение мотивов и цели позволяет установить фоору вины преступника.

Таким образом, за исключением деяний, указанных в ст. 109 и ст. 118 УК РФ, а также преступлений с фрормой вины, законодателем четко не определенной, все преступления против жизни и здоровья, указанные в гл. 16 УК РФ, характеризуются наличием фракультативных признаков, свойственных субъективной стороне. При этом их можно дифференцировать на две группы: преступления, для которых эмоции, мотивы или цели закрепляются в качестве признаков состава (конструктивных, квалифицирующих, привилегирующих), и преступления, которые характеризуются фактическим наличием факультативных признаков субъективной стороны, в законе, однако, не названных.

В науке и практике применения уголовного права без полемики признаются два фракультативных признака субъективной стороны преступления - мотив и цель [18]. Приверженцы исключения эмоционального состояния из их числа полагают, что оно не может выступать самостоятельным элементом психического отношения лица к общественно опасному деянию.

Указанная позиция представляется дискуссионной, так как уголовное законодательство устанавливает в качестве самостоятельного признака субъективной стороны преступления аффект (ст. 107 и 113 УК РФ). В свою очередь, аффект является разновидностью эмоционального «взрыва», что требует изучения эмоционального состояния преступника. Статья 106 УК РФ закрепляет психотравмирующую ситуацию одним из условий совершения противоправного деяния. Импульсивные действия при детоубийстве представляют собой эмоциональную разрядку, вызванную психотравмирующей ситуацией. Таким образом, в данном случае эмоции субъекта в момент совершения преступления подлежат уголовно-правовой оценке.

Кроме того, считаем, что применительно к ряду преступных деяний возникновение умысла, мотива и цели порождается эмоциональным состоянием лица. Так, при совершении аффектированного преступления эмоции находятся в основе формирования целей и мотивов, имея при этом в некоторых случаях самостоятельное значение при квалификации преступного деяния. В других случаях эмоции могут формироваться в процессе совершения преступления. Например, жалость к жертве, эмоциональный отклик на чужое страдание. Вместе с тем такие эмоции не учитываются в качестве признаков преступления, но в рамках оценки судом обстоятельств совершенного преступления при назначении наказания имеют большое значение. 
Закон особо указывает на наличие эмоций при регламентации отдельных составов преступлений, не рассматривая их как составляющую определенных мотивов и целей [19, с. 257].

В зарубежной литературе также отмечается, что только тщательный анализ эмоций субъекта преступления позволяет выявить модель преступника, а также выбрать соответствующую меру наказания [20].

Недооценка значения эмоций субъекта преступления в отечественной правоприменительной практике приводит к появлению противоречий и ошибок. Например, определением судебной коллегии по уголовным делам Краснодарского краевого суда от 03 сентября 2015 г. по делу № 22$5110 / 2015$ [21] отменен приговор Армавирского городского суда Краснодарского края от 24 июля 2015 г., а преступные деяния переквалифицированы с ч. 1 ст. 105 УК РФ на ч. 1 ст. 107 УК РФ. Согласно тексту судебного акта, Армавирским городским судом Краснодарского края неверно произведена оценка всех доказательств, в том числе не принято во внимание заключение стационарной судебно-психиатрической экспертизы - обвиняемый в момент совершения преступного деяния находился в состоянии афффекта. Судебная коллегия подчеркивает, что аффектированное состояние вызвано длительной психотравмирующей ситуацией, которая сложилась в результате систематического негативного воздействия на обвиняемого со стороны потерпевшего, выраженного в неоднократном совершении противоправных деяний и аморальных поступков с его стороны. Воздействие психотравмирующей ситуации - это процесс постепенного накапливания у обвиняемого отрицательных эмоций напряженности, кульминацией которого выступил в конечном счете эмоциональный взрыв, разрядка в виде совершения убийства, создавшего эту ситуацию.

Таким образом, эмоции субъекта преступления во время совершения преступлений против жизни и здоровья имеют самостоятельное уголовно-правовое значение и влияют на квалификацию преступного деяния или назначение наказания.

Установление каждого признака субъективной стороны преступления дает возможность в полном объеме реализовать основные принципы квалификации преступления - объективность, истинность, точность, полноту [22, с. 21].

Рассматривая уголовно-правовое значение фракультативных признаков субъективной стороны преступлений против жизни и здоровья, следует еще раз указать, что законодатель для ряда составов преступлений их закрепил в качестве конструктивных, указав в диспозиции статьи. Глава 16 УК РФ содержит указание на квалифицированные виды преступлений, составы которых содержат в качестве обязательных и подлежащих установлению обстоятельств низменные мотивы и цели преступного деяния. Последние, таким образом, исполняют роль квалифицирующих признаков. Эмоциональное состояние как признак субъективной стороны в этом значении в УК РФ не употребляется. Кроме того, глава 16 УК РФ в ст. 107, 116, 113 УК РФ установила обязательные привилегирующие признаки.

Таким образом, уголовное законодательство для ряда составов преступлений против жизни и здоровья закрепило в качестве обязательных факультативные признаки субъективной стороны.

Еще одним аспектом значения рассматриваемых признаков является то, что они могут служить в качестве отягчающих или смягчающих обстоятельств. Например, в приговоре Пушкинского городского суда Московской области по делу № 1-141/2015 от 14 мая 2015 г. суд в качестве обстоятельства, смягчающего наказание, указал на мотив сострадания к потерпевшему. Он проявился в том, что субъект преступления убил потерпевшего, который испытывал в результате длительной болезни фризическую боль и страдания [23].

В качестве примера можно привести и приговор Дюртюлинского районного суда Республики Башкортостан по делу № 1-103/2013 от 1 октября 2013 г. [24]. Согласно судебному акту, обвиняемый совершил преступления, предусмотренные ч. 1 ст. 116, ч. 1 ст. 111 УК РФ. В ходе судебного следствия установлено, что он после конфликта с потерпевшим уехал домой, где взял деревянную биту, и приехал обратно, чтобы отомстить за оскорбления в его адрес. В результате обвиняемый нанес потерпевшему телесные повреждения. В судебном акте указано, что по эпизоду нанесения телесных повреждений обстоятельством, отягчающим наказание, суд признает совершение преступления из мести за правомерные действия других лиц (п. «е.1» ч. 1 ст. 63 УК РФ).

Подводя итог изложенному, необходимо констатировать, что в уголовном законодательстве мотив и цель являются квалифицирующими признаками, а эмоции относятся к привилегирующим обстоятельствам для целого ряда преступлений. Анализируемые признаки преступных деяний служат и обстоятельствами, влияющими на выбор соответствующего вида наказания. Как отмечается в уголовно-правовой литературе, эмоциональное состояние, мотив и цель в равной степени относятся к конкретному составу преступления, к группам сходных составов (специальному составу) и к общему составу преступления [25, с. 98]. 
Некоторые ученые отмечают, что подразделение признаков состава на обязательные и факультативные возможно лишь при изучении общего понятия состава преступления, а в конкретном составе преступления все признаки необходимы [26, с. 3-4]. Данная точка зрения представляется спорной, так как факультативные признаки субъективной стороны преступного деяния содержатся в составах умышленных преступлений. Что касается конкретных случаев, то здесь они действительно выступают в качестве обязательного признака состава преступления.

Обращаясь к процессуальному праву, следует заметить, что в силу п. 3 ст. 220 и п. 4 ст. 225 УПК РФ по окончании расследования составляются обвинительный акт или заключение, которые должны содержать указание в том числе и на мотив, и на цель преступления. Вместе с тем в соответствии с п. 2 ст. 73 УПК РФ при производстве по уголовному делу подлежат доказыванию только вина и мотивы. В данном случае наблюдается противоречие между названными нормами. Кроме того, законодатель оставил без внимания оценку эмоционального состояния преступника.

На основании изложенного считаем необходимым скорректировать содержание п. 2 ст. 73 УПК РФ путем указания в нем всех признаков субъективной стороны преступления.

Полагаем, что материальное и процессуальное право должны дополнять друг друга, проявляя единое отношение ко всем имеющим правовое значение обстоятельствам. В их положениях не может быть противоречий.

Резюмируя сказанное, можно сделать вывод, что содержание субъективной стороны преступления раскрывается с помощью таких признаков, как вина, мотив, цель и эмоции. Каждый признак имеет самостоятельное значение, но при этом они взаимосвязаны между собой. Факультативные признаки субъективной стороны преступлений против жизни и здоровья личности играют весьма значимую роль при квалификации преступных деяний, они помогают разграничить смежные составы преступлений, способствуют дифференциации ответственности и индивидуализации наказания.

\section{Ссылки:}

1. Неустроева А.В., Веснина С.Н. Значение объективных данных произошедшего в получении информации о субъективной стороне преступления // Актуальные проблемы борьбы с преступностью в Дальневосточном фредеральном округе: материалы Всероссийской научно-практической конференции / ред. Е.П. Ким. Хабаровск, 2008. С. 116-120.

2. Маркарян С.А. Значение субъективной стороны преступления в уголовном законодательстве РФ // Пробелы в российском законодательстве. 2008. № 1. С. 271.

3. Рарог А.И. Квалификация преступлений по субъективным признакам. СПб., 2003. 359 с.

4. Российское уголовное право. Общая часть / под ред. В.П. Коняхина, М.Л. Прохоровой. М., 2014. 560 с.

5. Лекшас И. Вина как субъективная сторона преступления / под ред. Пионтковский А.А. М., 1958. 85 с.

6. Дагель П.С., Котов Д.П. Субъективная сторона преступления и ее установление. Воронеж, 1974. 243 с.

7. Васильев В.В. Теоретические проблемы субъективной стороны состава правонарушения // Вектор науки Тольяттинского государственного университета. Серия: Юридические науки. 2011. № 1 (4). С. 28-32.

8. Хатова Ж.М. Понятие состава административного правонарушения нуждается в законодательном закреплении // Административное право и процесс. 2007. № 1. С. 25-27.

9. Рарог А.И. Субъективная сторона и квалификация преступлений. М., 2001. 134 с.

10. Дагель П.С. Содержание, форма и сущность вины в советском уголовном праве // Правоведение. 1969. № 1. С. $78-88$.

11. Епифанов Б.В. Субъективная сторона преступления : лекция // Юридическая наука: история и современность. 2018. № 2. С. $138-160$.

12. Демидов Ю.А. Социальная ценность и оценки в уголовном праве. М., 1975. 182 с.

13. Чернова Н.А. Соотношение мотива совершения преступления и эмоций в уголовном праве // Актуальные проблемы российского права. 2016. № 9 (70). С. 116-121.

14. Рубинштейн С.Л. Основы общей психологии. М., 1946. С. 14.

15. Леонтьев А.Н. Потребности, мотивы и эмоции. М., 1971. 40 с.

16. Цельникер Г.Ф. Вина в российском праве: общетеоретический и исторический аспекты : автореф. дис. ... канд. юрид. наук. Нижний Новгород, 2004. 28 с.

17. О судебной практике по делам об убийстве (ст. 105 УК РФ) [Электронный ресурс]: постановление Пленума Верховного Суда РФ от 27.01.1999 № 1 : в ред. от 03.03.2015. Доступ из справ.-правовой системы «КонсультантПлюс».

18. Уголовное право России. Общая и Особенная части : учебник [Электронный ресурс] / А.А. Арямов, Т.Б. Басова, Е.В. Благов [и др.] ; отв. ред. Ю.В. Грачева, А.И. Чучаев. М., 2017. Доступ из справ.-правовой системы «КонсультантПлюс».

19. Российское уголовное право... С. 257.

20. Brubacher M.R. From Crime to Punishment: Moral Violations and the Social Function of Emotion [Электронный ресурс] : College of Science and Health Theses and Dissertations. Chicago, 2014. 197 p. URL: https://via.library.depaul.edu/csh_etd/89 (дата обращения: 28.04.2020).

21. Определение судебной коллегии по уголовным делам Краснодарского краевого суда от 03 сентября 2015 г. по делу № $22-$ 5110/2015 [Электронный ресурс] // Судебные и нормативные акты РФ. URL: https://sudact.ru/regular/doc/HhL3bjv878Hb/?regular-txt=\&regular-case_doc $=22-5110 \% 2 F 2015 \&$ regular-lawchunkinfo=\&regular-date_from=\&regular-date_to=\&regular-workflow_stage=\&regular-area=\&regular-court=Краснодарский+краевой+суд+\%28Краснодарский+край\%29\&regularjudge $=\&=1588068981550$ (дата обращения: 28.04.2020).

22. Рарог А.И. Проблемы квалификации преступлений по субъективным признакам : монография. М., 2016.232 с.

23. Приговор Пушкинского городского суда Московской области по делу № 1-141/2015 от 14 мая 2015 г. [Электронный ресурс] // Судебные и нормативные акты РФ. URL: https://sudact.ru/regular/doc/22qe6feWXIld/?regular-txt=\&regularcase_doc=1-141\%2F2015+\&regular-lawchunkinfo=\&regular-date_from=\&regular-date_to=\&regular-workflow_stage=\&regular- 
area=\&regular-court=Пушкинский+городской+суд+\%28Московская+область\%29\&regular-judge=\&_=1588068050875 (дата обращения: 28.04.2020).

24. Приговор Дюртюлинского районного суда Республики Башкортостан по делу № 1-103/2013 от 1 октября 2013 г. [Электронный ресурс] // Судебные и нормативные акты РФ. URL: https://sudact.ru/regular/doc/NfW7rMQDApWC/?regulartxt=\&regular-case_doc=1-103\%2F2013+\&regular-lawchunkinfo=\&regular-date_from=\&regular-date_to=\&regular-workflow_stage=\&regular-area=\&regular-court=Дюртюлинский+районный+суд+\%28Республика+Башкортостан\%29\&regular-jüge=\&_=1588067757314 (дата обращения: 28.04.2020).

25. Маслова Е.В. Факультативные признаки субъективной стороны состава преступления: теоретико-прикладное исследование : дис. ... канд. юрид. наук. М., 2018. 239 с.

26. Пинкевич Т.В. Криминологические и уголовно-правовые основы борьбы с экономической преступностью : дис. ... д-ра юрид. наук. М., 2002. 414 с.

Редактор: Хорева Людмила Николаевна Переводчик: Кочетова Дарья Андреевна 